\title{
Determinants of Usage Intention of LINE Users in Taiwan
}

\author{
Mei-Chun Chen1, Yung-Shen Yen ${ }^{2 *}$ \\ ${ }^{1}$ Department of Information Management, Vanung University, Taiwan \\ ${ }^{2}$ Department of Computer Science and Information Management, Providence University, Taiwan \\ Email: "ysyen@pu.edu.tw
}

Received 20 September 2015; accepted 24 October 2015; published 27 October 2015

Copyright (C) 2015 by authors and Scientific Research Publishing Inc.

This work is licensed under the Creative Commons Attribution International License (CC BY). http://creativecommons.org/licenses/by/4.0/

(c) () Open Access

\begin{abstract}
With the huge user base, LINE has become an important medium of mobile communications in the world. This study attempts to explore the factors influencing usage intention for LINE users. Drawing on the theory of planned behavior (TPB), this study adds three antecedents, including perceived enjoyment, perceived critical mass, and self-efficacy into the TPB model, and further examines the moderating effect of frequent users on the causal relationships. A structural equation modeling is used and 458 LINE users in Taiwan are investigated. The results reveal that perceived enjoyment and perceived critical mass are positively associated with behavioral attitude. Also, self-efficacy is positively associated with perceived behavioral control. Moreover, behavioral attitude, subjective norms, and perceived behavioral control are positively associated with usage intention, and the causal relationships are significantly varied between frequent and infrequent users.
\end{abstract}

\section{Keywords}

The Theory of Planned Behavior, Perceived Enjoyment, Perceived Critical Mass, Usage Intention, LINE

\section{Introduction}

Nowadays, people would like to connect mobile friends through social networking sites, such as LINE, WeChat, WhatsApp, Facebook, etc. In particular, LINE is one of the popular and heavily used by mobile users in the specific countries, such as Japan, Chinese Taipei, Thailand, etc. In Taiwan, LINE user enrollment has 17 million, over the half of 23 million of Taiwan's population [1]. With the huge user base, LINE has become an important

${ }^{*}$ Corresponding author. 
medium of mobile communications. Thus, the understanding of the factors influencing usage intention of LINE users is important for practitioners to manage the relationship with customers.

The theory of planned behavior (TPB), an extension of the theory of reasoned action (TRA), is a behavioral theory regarding the individual's intention to perform a given behavior. Behavioral attitude, subjective norms, and perceived behavioral control are three determinants influencing intention and actual behavior [2]. Specifically, subjective norms are similar to social influence, meaning that individuals adapt their attitudes and behaviors to their social situations [3]. Perceived behavioral control affected by self-efficacy is the confidence in one's ability to make a purchase decision [4]. Behavioral attitude refers to the way that individuals respond to and are disposed towards an object [5]. The antecedents of behavior attitude may be varied, depending on the service settings. For example, technology acceptance model posits that perceived ease of use and perceived usefulness are two antecedents influencing behavior attitude. However, according to the characteristics of LINE service, it is assumed that perceived enjoyment and perceived critical mass are the key antecedents influencing usage intention because its mechanism is for social communication [6]. Moreover, the causal relationship of influencing usage intention may be varied between frequent and infrequent users. Therefore, we may ask "How do the antecedents influence usage intention for LINE users?", and "Is the causal relationship among the variables varied between frequent and infrequent users?”. The field has not yet provided direct investigation.

To fill the research gap, we investigate the behaviors of a selected group of LINE users in Taiwan. It thereby contributes a few significant theoretical results to the field: extending the previous understanding of the TPB model for LINE users; and formulating a research framework to explain the causal relationships for usage intention across frequent and infrequent users. Moreover, it can also help practitioners to manage customer relationships in context of LINE service.

\section{Research Framework and Hypotheses Development}

Figure 1 depicts the research framework of this study, in terms of the above arguments.

According to the research framework, this study proposed:

H1: Perceived enjoyment is positively associated with behavioral attitude;

H2: Perceived critical mass is positively associated with behavioral attitude;

H3: Self-efficacy is positively associated with Perceived behavioral control;

H4: Behavioral attitude is positively associated with usage intention;

H5: Subject norms are positively associated with usage intention;

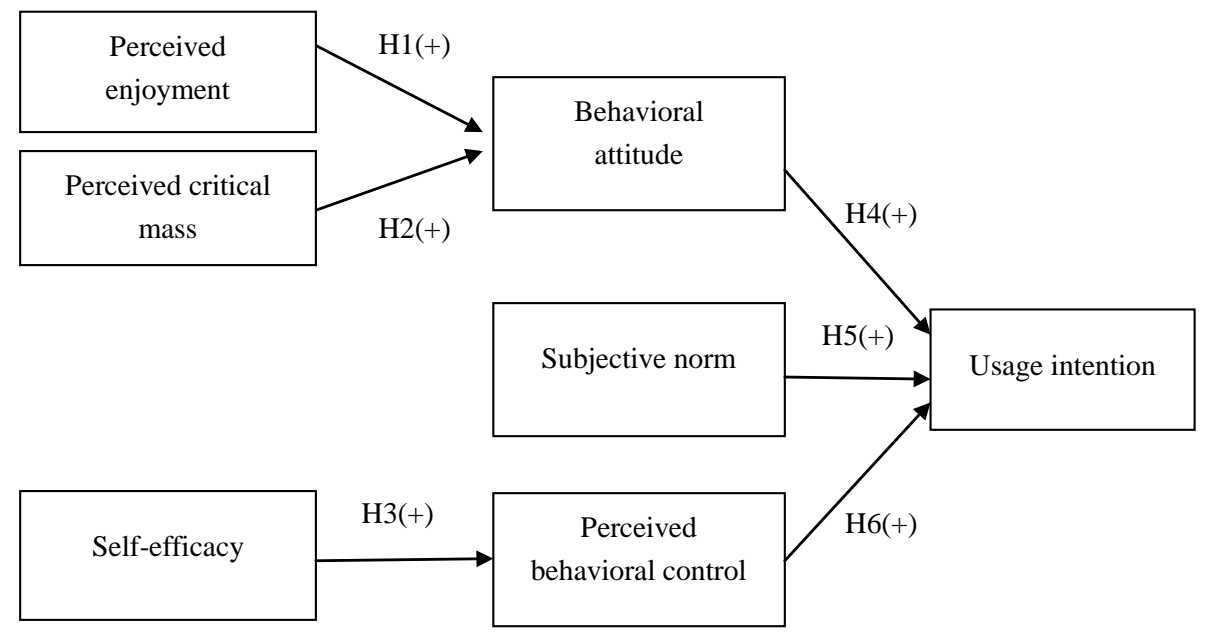

$\mathrm{H} 7$

Moderators: Frequent users

Figure 1. Research framework of this study. 
H6: Perceived behavioral control is positively associated with usage intention;

H7: The causal relationship among the variables is moderated by frequent users.

\section{Research Method}

\subsection{The Instrument of the Study}

The design of the instrument is adopted from previous results in the literature with appropriate modifications for LINE users (e.g. terminologies). The scale of perceived enjoyment was revised from Moon and Kim [7], which includes three items. The scale of perceived critical mass was revised from Ellison et al. [8], which includes three items. The scale of self-efficacy was revised from George [9], which includes three items. The scales of behavioral attitude and subjective norms were revised from Taylor and Todd [10], which includes two items and three items respectively. The scale of usage intention was revised from Moon and Kim [7], which includes three items. All of the items were measured on a 7-point Likert-type scale, where possible answers ranged from strongly disagree (1) to strongly agree (7). The instrument of the study is shown in Table 1.

\subsection{Subjects}

The sample of this study is from Taiwan. The main reason is that LINE is up to a total of 230 million registered users in August 2013 [11]. In terms of the use proportion of population, Chinese Taipei obviously is the biggest country to use LINE in the world. Thus, it has representative to investigate the LINE users in Taiwan.

This study conducted an online survey. The questionnaire was translated by a language professional to ensure that the wording used in the Chinese and English versions were consistent. In the announcement, we declared the purpose of the study and the qualifications for participating in the survey. The respondents were informed that their responses are anonymous and only for academic purposes. The questionnaire was posted in the Google online survey system, which links to PTT (ptt.cc) website, the largest bulletin board system in Taiwan. The respondents who have the experience of LINE were invited to participate in the survey. To increase the sample return rate, this study offered gifts to the respondents for increasing the participation to the survey.

The questionnaires were collected for one month. A total of 470 respondents were received, of which 12 copies were deleted due to regular or incomplete data. The valid respondents totaled 458 . The demography of the respondents is shown in Table 2. Females (52.8\%) surpass males (47.2\%). The largest age group is 40 - 49 years (32.3\%), and the largest education group is undergraduate (62.2\%). Regarding the frequency of using LINE in the past three months, most of the respondents use LINE every day or almost every day (36.5\%).

In addition, the measurement of frequent users in the study was revised from Johnson [12], which classified the frequent user group as the users who use the Internet a few times a week or every day or almost every day, and the infrequent user group as the users who never or rarely use the Internet. As thus, frequent users in this study totaled 270 (58.9\%), whereas infrequent users totaled 113 (24.7\%).

Table 1. Construct and definition.

\begin{tabular}{|c|c|c|c|}
\hline Construct & Operational definition & Number of measurement items & Source \\
\hline Perceived enjoyment & $\begin{array}{l}\text { The extent to which an individual perceives using } \\
\text { LINE is enjoyable. }\end{array}$ & 3 & [7] \\
\hline Perceived critical mass & $\begin{array}{l}\text { The point at which enough individuals have used } \\
\text { LINE so that the further rate of adoption } \\
\text { becomes self-sustaining. }\end{array}$ & 3 & [8] \\
\hline Self-efficacy & $\begin{array}{l}\text { An individual's beliefs about his or her capabilities } \\
\text { to use LINE. }\end{array}$ & 3 & {$[9]$} \\
\hline Behavioral attitude & An individual's overall evaluation toward using LINE. & 3 & {$[10]$} \\
\hline Subjective norms & $\begin{array}{l}\text { Users' perception of whether other important people } \\
\text { perceive they should use LINE. }\end{array}$ & 2 & {$[10]$} \\
\hline Perceived behavioral control & $\begin{array}{l}\text { Users' perception if they have the necessary resources } \\
\text { and capability in successfully using LINE. }\end{array}$ & 3 & [10] \\
\hline Usage intention & An individual's behavioral intention to use LINE. & 3 & [7] \\
\hline
\end{tabular}




\subsection{Reliability and Validity Test}

This study employed Cronbach's alpha $(\alpha)$ for examining the internal consistency of the constructs [13] [14]. The $\alpha$ in Table 3 indicates the reliability of the measurement constructs: perceived enjoyment is 0.92, perceived critical mass is 0.91 , behavioral attitude is 0.90 , subjective norms are 0.83 , perceived behavioral control is 0.84 , and usage intention is 0.95 . These numbers satisfy the general requirements in the field (e.g. [13]) suggest a reliability coefficient above 0.7, and Robert and Wortzel [14] want the number to be between 0.70 and 0.98 . Therefore, we content that this study carried good reliability.

Table 2. Demography of the respondents.

\begin{tabular}{|c|c|c|c|}
\hline Variables & Items & $N$ & Percent (\%) \\
\hline \multirow{2}{*}{ Gender } & Male & 216 & 47.2 \\
\hline & Female & 242 & 52.8 \\
\hline \multirow{4}{*}{ Age } & $20-29$ & 117 & 25.5 \\
\hline & $30-39$ & 131 & 28.6 \\
\hline & $40-49$ & 148 & 32.3 \\
\hline & $>49$ & 62 & 13.6 \\
\hline \multirow{3}{*}{ Education } & Senior high school & 38 & 8.3 \\
\hline & Undergraduate & 285 & 62.2 \\
\hline & Graduate & 135 & 29.5 \\
\hline \multirow{5}{*}{ Frequency of using LINE in the past three months } & Never & 42 & 9.2 \\
\hline & Rarely & 71 & 15.5 \\
\hline & A few times a month & 75 & 16.4 \\
\hline & A few times a week & 103 & 22.4 \\
\hline & Every day or almost every day & 167 & 36.5 \\
\hline
\end{tabular}

Note: valid samples $=458$.

Table 3. Model of research construct.

\begin{tabular}{|c|c|c|c|c|c|}
\hline Construct and observable variable & Mean (SD) & SFL & CR & AVE & $\alpha$ \\
\hline Perceived enjoyment (PE) & & & 0.92 & 0.80 & 0.92 \\
\hline PE1 & $4.16(1.76)$ & 0.84 & & & \\
\hline PE2 & $4.31(1.78)$ & 0.96 & & & \\
\hline PE3 & $4.45(1.70)$ & 0.88 & & & \\
\hline Perceived critical mass (PCM) & & & 0.91 & 0.78 & 0.91 \\
\hline PCM1 & $5.66(1.45)$ & 0.87 & & & \\
\hline PCM2 & $5.67(1.44)$ & 0.91 & & & \\
\hline РCM3 & $5.54(1.39)$ & 0.87 & & & \\
\hline Behavioral attitude (ATT) & & & 0.72 & 0.88 & 0.90 \\
\hline ATT1 & $5.40(1.32)$ & 0.89 & & & \\
\hline ATT2 & 5.39 (1.38) & 0.88 & & & \\
\hline ATT3 & $5.28(1.52)$ & 0.77 & & & \\
\hline Subjective norms (SN) & & & 0.85 & 0.74 & 0.83 \\
\hline SN1 & $4.48(1.65)$ & 0.97 & & & \\
\hline SN2 & $4.67(1.72$ & 0.73 & & & \\
\hline Perceived behavioral control (PBC) & & & 0.85 & 0.66 & 0.84 \\
\hline PBC1 & $5.33(1.52)$ & 0.64 & & & \\
\hline PBC2 & $5.42(1.48)$ & 0.91 & & & \\
\hline PBC3 & $5.76(1.59)$ & 0.86 & & & \\
\hline Usage intention (UI) & & & 0.94 & 0.85 & 0.95 \\
\hline UI1 & $5.44(1.49)$ & 0.91 & & & \\
\hline UI2 & $5.39(1.50)$ & 0.96 & & & \\
\hline UI3 & $5.20(1.55)$ & 0.89 & & & \\
\hline
\end{tabular}


Confirmation factor analysis (CFA) was performed for scale validity assessment [15]. Convergent validity was measured by average variance extracted (AVE) in each construct. The criterion of AVE should be greater than 0.5 [16]. The evidence showed in Table 3 reveals that all constructs were satisfied. Thus, this study possessed adequate convergent validity.

Discriminate validity was also tested. The result shows that the AVE square root of each research variable is larger than the related coefficients of the variables, as shown in Table 4. This is a clear case of positive proof [16]. Thus, this study had adequate discriminate validity.

\subsection{Measurement Invariance Tests}

In order to compare the causal relationship of the variables between frequent and infrequent users, this study conducted multiple-group confirmatory factor analysis for testing measurement invariance across gender. The degree of invariance is frequently assessed by the differences in $\chi^{2}$ between the models [17]. If $\Delta \chi^{2}$ is not statistically significant, then the invariance exists. Table 5 shows the results of measurement invariance tests. The evidence reveals that factorial invariance (i.e. same factor loadings across gender) and structural invariance (i.e. same factor loadings and factor covariance across gender) both are not significant between frequent and infrequent users $\left(\Delta \chi^{2}(11)=6.377, p>0.05 ; \Delta \chi^{2}(21)=36.418, p>0.05\right)$, but error invariance (i.e. same factor loadings, factor covariance, and error variance across gender) is significant $\left(\Delta \chi^{2}(17)=491.602, p<0.05\right)$. This result implies that factorial invariance model and structural invariant model are invariant, but error invariance model is non-variant. However, it is widely accepted that the test of error variance and their covariance represents an overly restrictive test of the data [18]. Thus, we believe that measurement invariance does exist in this study.

\section{Analysis of Empirical Results}

\subsection{Verification of the Hypotheses}

A structural equation modeling using AMOS 20.0 was conducted to test the postulated hypotheses. Figure 2 presented the estimation results. From the model fitness indexes, $\chi^{2}=289.560, \mathrm{DF}=114, \chi^{2} / \mathrm{DF}=2.54$, GFI $=$ 0.938 , AGFI $=0.913$, CFI $=0.962$, RMSEA $=0.067$, showing the collected data fits the postulated model. The estimated structural coefficients were used to test each hypothesis. Results in Table 6 showed that the model explained $57.9 \%, 42.6 \%$ of the variance in behavioral attitude and perceived behavioral control, and $67.5 \%$ of

Table 4. Correlation between constructs.

\begin{tabular}{ccccccc}
\hline Construct & PE & PCM & ATT & SN & PBC & UI \\
PE & $\mathbf{0 . 8 9}$ & & & & \\
PCM & 0.37 & $\mathbf{0 . 8 8}$ & & & & \\
ATT & 0.29 & 0.56 & $\mathbf{0 . 9 4}$ & & & \\
SN & 0.31 & 0.48 & 0.37 & $\mathbf{0 . 8 6}$ & & 0.26 \\
PBC & 0.34 & 0.30 & 0.31 & 0.81 & $\mathbf{0 . 9 2}$ \\
\hline UI & 0.42 & 0.45 & 0.63 & 0.43 & 0.46 & \\
\hline
\end{tabular}

Note: Diagonal elements in boldface represent the square root of AVE.

Table 5. Results of measurement invariance tests.

\begin{tabular}{cccccccccc}
\hline Model & NPAR & $\Delta \chi^{2}$ & DF & $\Delta \chi^{2}$ & $\Delta$ DF & $P$ & $\Delta$ TLI & $\Delta$ CFI \\
\hline Base model & 98 & 504.461 & 208 & & & & & -0.001 \\
Factorial invariance & 87 & 510.837 & 219 & 6.377 & 11 & 0.847 & -0.004 & 0.003 & 0.007 \\
Structural invariance & 66 & 547.256 & 240 & 36.418 & 21 & 0.126 & 0.003 \\
Error invariance & 49 & 1038.857 & 257 & 491.602 & 17 & 0.000 & 0.073 & 0.072 \\
\hline
\end{tabular}




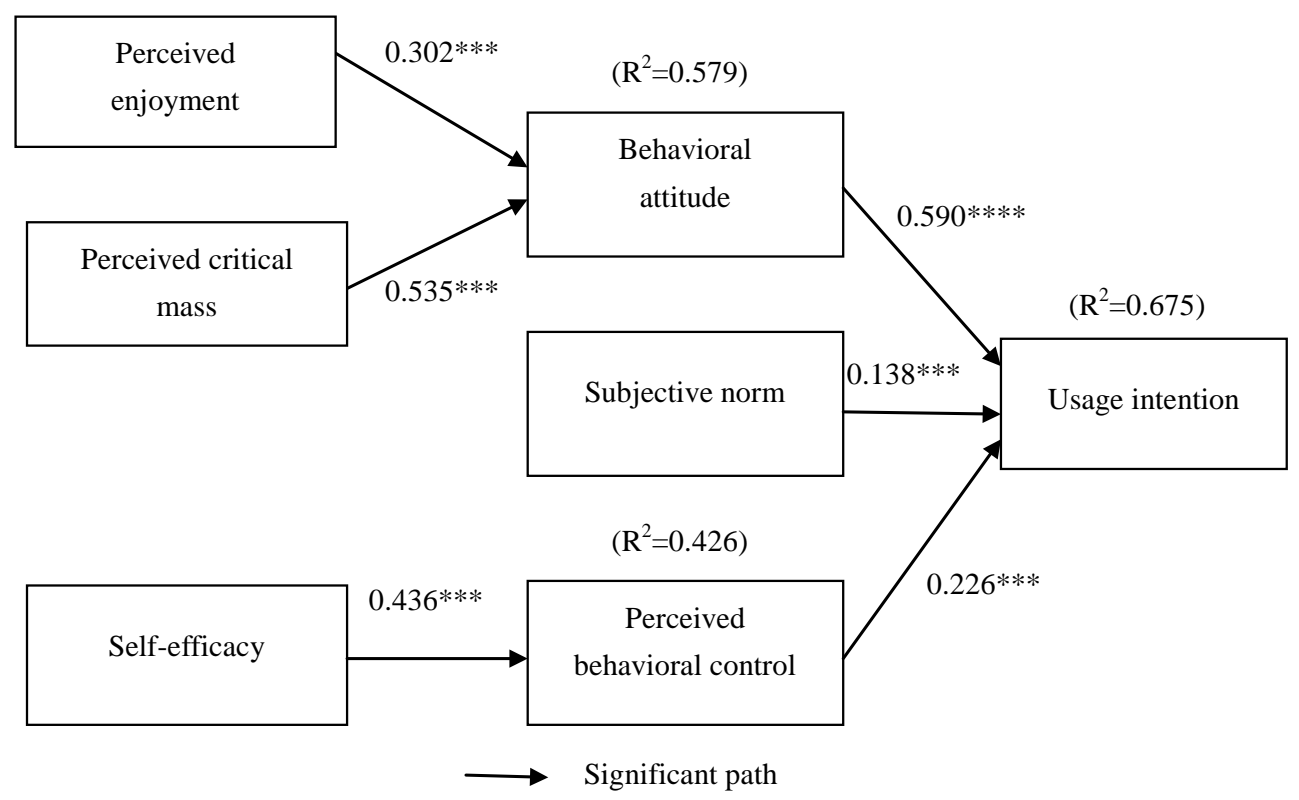

Figure 2. Results of structural modeling analysis. Note: ***means significant at the level of 0.001 .

Table 6. Results of estimated structural coefficients.

\begin{tabular}{cccccc}
\hline Relationship & Estimate & SE & CR & P & Result \\
\hline H1. PE $\rightarrow$ ATT & 0.302 & 0.038 & 7.857 & $* * *$ & Support \\
H2. PCM $\rightarrow$ ATT & 0.535 & 0.047 & 11.312 & $* * *$ & Support \\
H3. SE $\rightarrow$ PBC & 0.436 & 0.037 & 9.472 & $* * *$ & Support \\
H3. ATT $\rightarrow$ UI & 0.590 & 0.040 & 14.650 & $* * *$ & Support \\
H4. SN $\rightarrow$ UI & 0.138 & 0.036 & 3.881 & $* * *$ & Support \\
H5. PBC $\rightarrow$ UI & 0.226 & 0.047 & 4.810 & $* * *$ & Support \\
\hline
\end{tabular}

Note: Estimate is unstandardized; *** means significant at the level of 0.001.

the variance in usage intention. All paths in the research model were statistically significant at the level of 0.001 . Perceived enjoyment and perceived critical mass are positively associated with behavioral attitude (Estimate $=$ $0.302, \mathrm{SE}=0.038, \mathrm{CR}=7.857, p<0.001$; Estimate $=0.535, \mathrm{SE}=0.047, \mathrm{CR}=11.312, p<0.001$ ). Self-efficacy is positively associated with perceived behavioral control (Estimate $=0.436, \mathrm{SE}=0.037, \mathrm{CR}=9.472, p<0.001$ ). Moreover, behavioral attitude, subjective norms, and perceived behavioral control are positively associated with usage intention (Estimate $=0.590, \mathrm{SE}=0.040, \mathrm{CR}=14.650, p<0.001$; Estimate $=0.138, \mathrm{SE}=0.036, \mathrm{CR}=$ 3.881, $p<0.001$; Estimate $=0.226, \mathrm{SE}=0.047, \mathrm{CR}=4.810, p<0.001$ ). Thus, H1, H2, H3, H4, H5, and H6 are supported.

Multiple group structural equation modeling was conducted to test the differences of the causal relationships across two groups. Yang and Lee [19] suggested that significant differences in two groups were determined by using a $\chi^{2}$ difference test. As thus, Table 7 showed that full constrained model with limited the same path coefficients between frequent users and infrequent users is significant $\left(\Delta \chi^{2} / 6=12.262, p=0.031\right)$. In addition, the path between subjective norms and usage intention, and the path between perceived behavioral control and usage intention all are significant $\left(\Delta \chi^{2} / 1=5.889, p=0.015 ; \Delta \chi^{2} / 1=5.694, p=0.017\right)$, but other paths are insignificant across frequent users and infrequent users. For more details, Figure 3 and Figure 4 showed the results of estimated structural modeling analysis for frequent users and infrequent users respectively. Moreover, the path between subjective norms and usage intention and the path between perceived behavioral control and usage intention both are significant for frequent users (Estimate $=0.123, \mathrm{SE}=0.037, \mathrm{CR}=3.366, p<0.001$; Estimate 
Table 7. The moderating effect of frequent users.

\begin{tabular}{cccc}
\hline Path & $\chi^{2}$ & DF & $P$ \\
\hline Full constrained model & 12.262 & 6 & $0.031^{*}$ \\
Path 1: PE $\rightarrow$ ATT & 2.683 & 1 & 0.101 \\
Path 2: PCM $\rightarrow$ ATT & 2.081 & 1 & 0.138 \\
Path 3: SE $\rightarrow$ PBC & 1.653 & 1 & 0.225 \\
Path 4: ATT $\rightarrow$ UI & 2.079 & 1 & 0.149 \\
Path 5: SN $\rightarrow$ UI & 5.889 & 1 & $0.015^{*}$ \\
Path 6: PBC $\rightarrow$ UI & 5.694 & 1 & $0.017^{*}$ \\
\hline
\end{tabular}

Note: *means significant at the level of 0.05 .

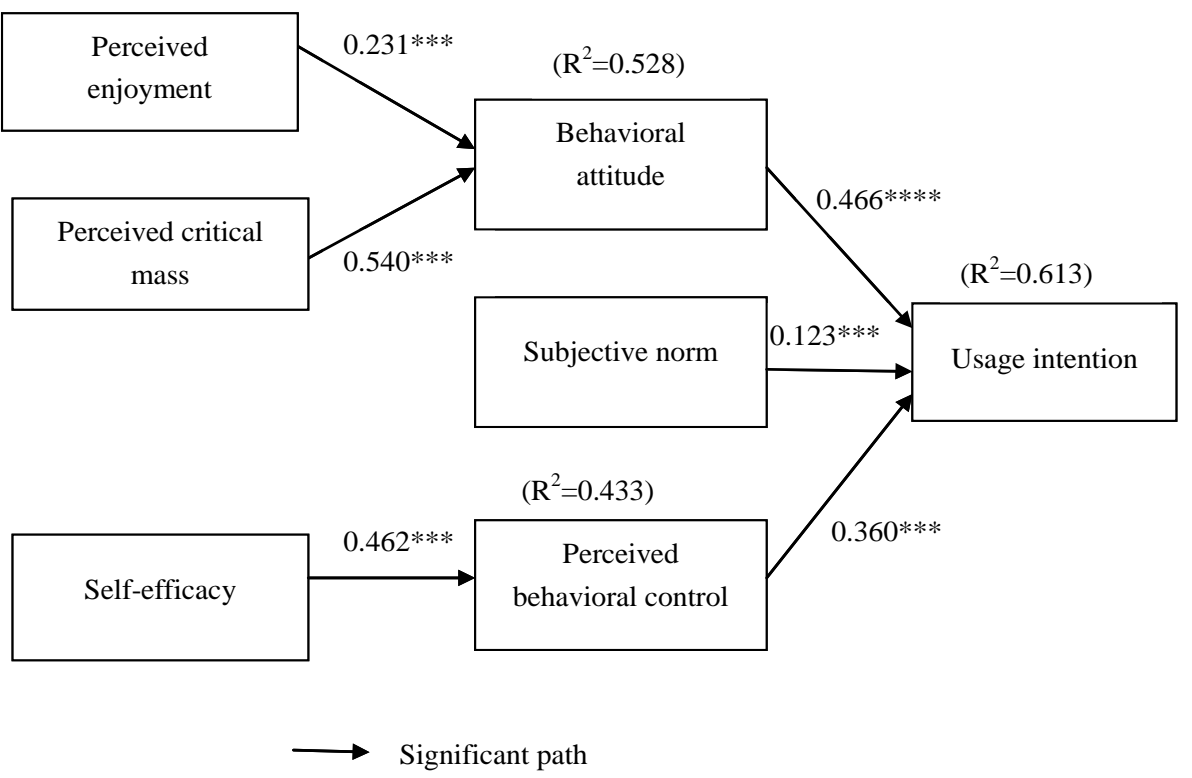

Figure 3. Results of structural modeling analysis for frequent users. Note: *** means significant at the level of 0.001 .

$=0.360, \mathrm{SE}=0.062, \mathrm{CR}=5.829, p<0.001)$, but insignificant for infrequent users (Estimate $=0.088, \mathrm{SE}=$ $0.101, \mathrm{CR}=0.869, p=0.385$; Estimate $=0.055$, $\mathrm{SE}=0.085, \mathrm{CR}=0.648, p=0.517$ ), as shown in Table 8 . Thus, H7 is supported.

\subsection{Discussion}

The study has yielded several important findings. First, it affirms that behavior attitude, subjective norms, and perceived behavioral control are positively associated with usage intention. This result is in line with the study of Ajzen [2], which asserted that behavioral intention is a function of attitude, subjective norms, and perceived behavioral control. This study also finds that perceived enjoyment and perceived critical mass are two important antecedents influencing behavior attitude for the users. Obviously, three main forces, including behavior attitude, subjective norms and perceived behavioral control, influence LINE users to use the service. Thus, the TPB model has been confirmed in the context of LINE service. This result implies that perceived enjoyment and perceived critical mass are two important antecedents influencing behavior attitude, which in turn increases usage intention for LINE users. It is believed that users can get more fun and communicate with more people in LINE service. Moreover, subjective norms also affect usage intention for LINE users. Indeed, peer pressure can encourage users to participate the service for communicating with friends in the mobile community. Furthermore, 

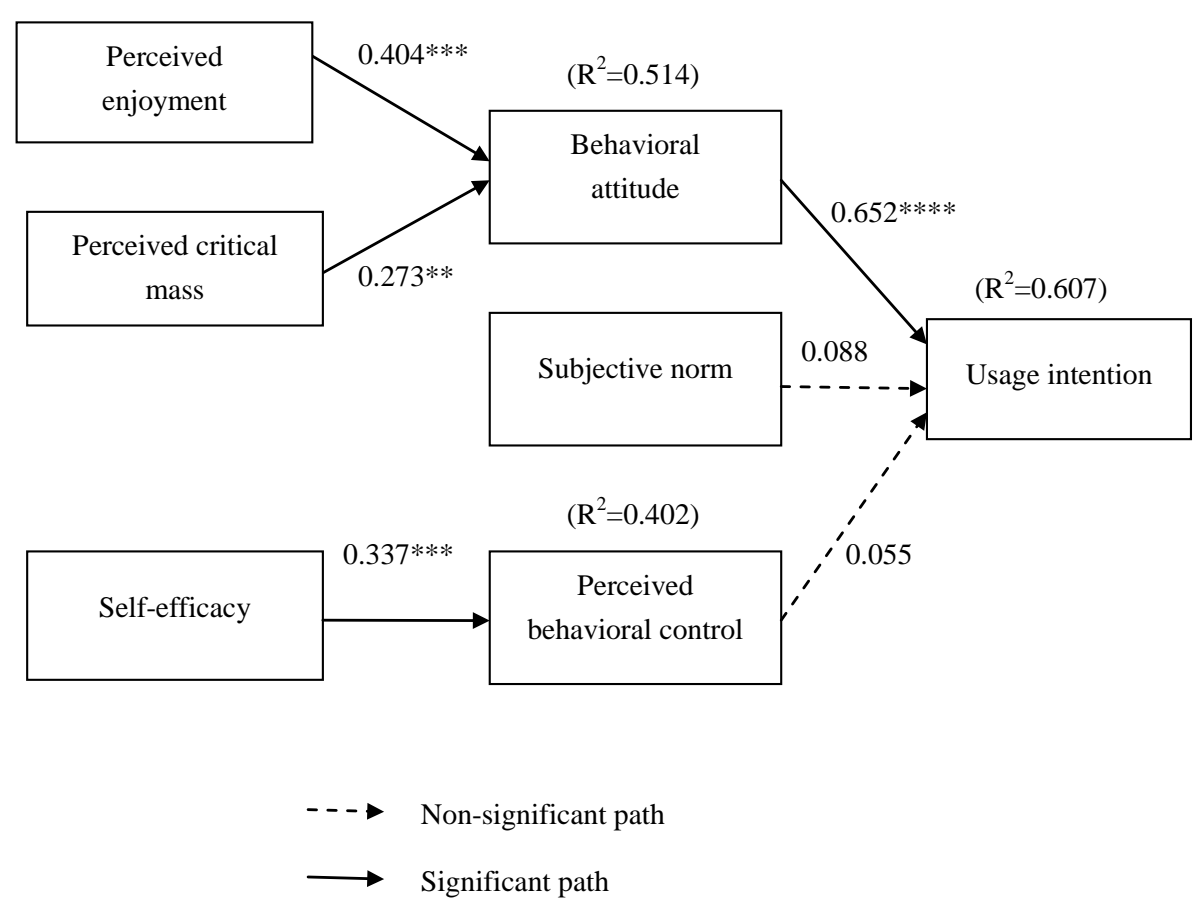

Figure 4. Results of structural modeling analysis for infrequent users. Note: **means significant at the level of $0.01 ; * *$ means significant at the level of 0.001 .

Table 8. Results of coefficients between frequent users and infrequent users.

\begin{tabular}{ccccc}
\hline Relationship & Estimate & SE & CR & $P$ \\
\hline Frequent users $(N=$ 270) & & & & \\
Path 1: $\mathrm{PE} \rightarrow$ ATT & 0.231 & 0.041 & 5.673 & $* * *$ \\
Path 2: PCM $\rightarrow$ ATT & 0.540 & 0.059 & 9.094 & $* * *$ \\
Path 3: $\mathrm{SE} \rightarrow$ PBC & 0.462 & 0.038 & 10.573 & $* * *$ \\
Path 4: $\mathrm{ATT} \rightarrow$ UI & 0.466 & 0.043 & 10.931 & $* * *$ \\
Path 5: SN $\rightarrow$ UI & 0.123 & 0.037 & 3.366 & $* * *$ \\
Path 6: $\mathrm{PBC} \rightarrow$ UI & 0.360 & 0.062 & 5.829 & $* * *$ \\
Infrequent users $(N=$ 113) & & & & \\
Path 1: PE $\rightarrow$ ATT & 0.404 & 0.088 & 4.580 & $* * *$ \\
Path 2: PCM $\rightarrow$ ATT & 0.273 & 0.083 & 3.275 & $0.001^{* *}$ \\
Path 3: SE $\rightarrow$ PBC & 0.337 & 0.092 & 3.728 & $* * *$ \\
Path 4: ATT $\rightarrow$ UI & 0.652 & 0.113 & 5.744 & $* * *$ \\
Path 5: SN $\rightarrow$ UI & 0.088 & 0.101 & 0.869 & 0.385 \\
Path 6: PBC $\rightarrow$ UI & 0.055 & 0.085 & 0.648 & 0.517 \\
\hline
\end{tabular}

Note: Estimate is unstandardized; **means significant at the level of $0.01 ; * * *$ means significant at the level of 0.001 .

self-efficacy is another antecedent to influence usage intention in the LINE. Maddux [20] argued that if a person has higher self-efficacy in a particular job, this will make him/her more active participation in efforts to complete the task or the job. Thus, a person's self-efficacy in the use of LINE can influence perceived behavioral control to the service, which in turn increases usage intention. 
Second, this study also finds that the effect of behavioral attitude on usage intention (Estimate $=0.590$ ) is stronger than the effects of subjective norms and perceived behavioral control (Estimate $=0.138$; Estimate $=$ 0.226). This finding implies that behavioral attitude is a major determinant influencing usage intention for LINE users. The possible reason is that users may likely enjoy the communication with many friends to enhance usage intention in LINE service, followed by the effects of perceived behavioral control and subjective norms.

Third, interestingly, this study found that the causal relationship is varied between frequent and infrequent users. In particular, the intention is only influenced by behavioral attitude for infrequent users, but for frequent users, usage intention is affected by behavioral attitude, subjective norms and perceived behavioral control. The possible reason is that users who are infrequent use of LINE service may lack of interactive targets and the ability of self-efficacy to user the services. Thus, they may passively use the services when some people "line" them.

\section{Conclusions}

In conclusion, the findings of the study provided both theoretical and practical benefits. From a theoretical perspective, this study affirmed the effects of perceived enjoyment, perceived critical mass, and self-efficacy on the relationships of the TPB model. We verified that attitudinal beliefs regarding perceived enjoyment and perceived critical mass, as well as subjective norms and perceived behavioral control influenced usage intention in LINE service. Therefore, this study advanced the previous understanding of usage intention in the context of LINE service.

From a practical perspective, this study suggested that practitioners should provide the effective communication tools for helping users to establish the relationships with their friends. They needed to design the funny stickers for users to increase the enjoyment with friends in LINE service. With respect to perceived critical mass, practitioners shall promote LINE service in the countries that people who was the less or never use of LINE service. In terms of infrequent users, practitioners shall encourage users to invite their friends to participate in the mobile community, as well as bring forth the self-efficacy in LINE service.

Along with these important findings, this study had some limitations. First, bias might exist due to the sampling taken through an online survey on a specific website. Second, the research model used in this study was intentionally simplified. The constructs in the proposed model accounted for only approximately $67.5 \%$ of the variance of usage intention, indicating that some of the important predictors might be missing. Excepting for internal and external motivations, security of personal data might be important to influence the use of LINE. Thus, subsequent studies might add security as a control variable in the model to further enhance the variance of usage intention in LINE service. Third, this study used a cross-sectional data to analyze the causal relationships for usage intention in LINE service. The results would only be inferred rather than proven [21]. Thus, subsequent studies might conduct a longitudinal approach to identify the dynamic change of the relationships in the TPB model.

\section{References}

[1] Tsao, W.Y. (2014) Enhancing Competitive Advantages: The Contribution of Mediator and Moderator on Stickiness in the LINE. Journal of Retailing and Consumer Services, 21, 933-941. http://dx.doi.org/10.1016/j.jretconser.2014.08.011

[2] Ajzen, I. (1991) The Theory of Planned Behavior. Organizational Behavior and Human Decision Processes, 50, 179211. http://dx.doi.org/10.1016/0749-5978(91)90020-T

[3] Salancik, G.R. and Pfeffer, J. (1978) Social Information-Processing Approach to Job Attitudes and Task Design. Administrative Science Quarterly, 23, 224-253. http://dx.doi.org/10.2307/2392563

[4] Bandura, A. (1986) Social Foundations of Thought and Action. Prentice-Hall, Englewood Cliffs.

[5] Teo, T. and Lee, C.B. (2010) Explaining the Intention to Use Technology among Student Teachers: An Application of the Theory of Planned. Campus-Wide Information Systems, 27, 60-67. http://dx.doi.org/10.1108/10650741011033035

[6] Ball, P. (2004) Critical Mass: How One Thing Leads to Another. Farrar, Straus and Giroux.

[7] Moon, J.-W. and Kim, Y.-G. (2001) Extending the TAM for a World-Wide-Web Context. Information \& Management, 38, 217-230. http://dx.doi.org/10.1016/S0378-7206(00)00061-6

[8] Ellison, N., Steinfield, C. and Lampe, C. (2006) Spatially Bounded Online Social Networks and Socialcapital: The Role of Facebook. The Annual Conference of the International Communication Association, 36, 1-37.

[9] George, J.F. (2004) The Theory of Planned Behavior and Internet Purchasing. Internet Research, 14, 198-212. 
http://dx.doi.org/10.1108/10662240410542634

[10] Taylor, S. and Todd, P.A. (1995) Understanding Information Technology Usage: A Test of Competing Models. Information Systems Research, 6, 144-176. http://dx.doi.org/10.1287/isre.6.2.144

[11] Millward, S. (2013) Line Reveals latest User Numbers in Japan, Thailand, Chinese Taipei, Indonesia. https://www.techinasia.com/line-user-numbers-thailand-indonesia-japan-taiwan-august-2013/

[12] Johnson, G.M. (2008) Cognitive Processing Differences between Frequent and Infrequent Internet Users. Computers in Human Behavior, 24, 2094-2106. http://dx.doi.org/10.1016/j.chb.2007.10.001

[13] Nunnally, J.C. (1978) Psychometric Theory. 2nd Edition, McGraw-Hill, New York.

[14] Robert, M.L. and Wortzel, L.H. (1979) New Life-Style Determinants of Women's Food Shopping Behavior. Journal of Marketing, 43, 28-39. http://dx.doi.org/10.2307/1250144

[15] Anderson, J. and Gerbing, D.W. (1988) Structural Equation Modeling in Practice: A Review and Recommended Two-Step Approach. Psychological Bulletin, 103, 411-423. http://dx.doi.org/10.1037/0033-2909.103.3.411

[16] Fornell, C. and Larcker, D.F. (1981) Evaluating Structural Equations with Unobservable Variables and Measurement error. Journal of Marketing Research, 18, 39-50. http://dx.doi.org/10.2307/3151312

[17] Cheung, G.W. and Rensvold, R.B. (2002) Evaluating Goodness-of-Fit Indexes for Testing Measurement Invariance. Structural Equation Modeling: A Multidisciplinary Journal, 9, 233-255. http://dx.doi.org/10.1207/S15328007SEM0902_5

[18] Byrne, B.M. (2010) Structural Equation Modeling with AMOS. Routledge, New York.

[19] Yang, K. and Lee, H.-J. (2010) Gender Differences in Using Mobile Data Services: Utilitarian and Hedonic Value Approaches. Journal of Research in Interactive Marketing, 4, 142-156. http://dx.doi.org/10.1108/17505931011051678

[20] Maddux, J.E. (1995) Self-Efficacy, Adaptation, and Adjustment: Theory, Research, and Application. Plenum Press, New York. http://dx.doi.org/10.1007/978-1-4419-6868-5

[21] Fang, Y.-H., Chiu, C.-M. and Wang, E.T.G. (2011) Understanding Customers' Satisfaction and Repurchase Intentions-An Integration of IS Success Model, Trust, and Justice. Internet Research, 21, 479-503. http://dx.doi.org/10.1108/10662241111158335 


\section{Appendix 1. The Instrument of the Study}

Perceived enjoyment (PE) (adapted from [7])

PE1: Using LINE gives enjoyment to me;

PE2: Using LINE gives fun to me;

PE3: Using LINE keeps me happy.

Perceived critical mass (PCM) (adapted from [8])

PCM1: Many people I communicated with use LINE;

PCM2: Among the people I communicated with regularly, many use LINE;

PCM3: The people I communicated with will continue to use LINE in the future.

Self-efficacy (SE) (adapted from [9])

SE1: I would feel comfortable using LINE on my own;

SE2: If I wanted to, I could easily use LINE on my own;

SE3: I would be able to use LINE even if there was no one around to show me how to is.

Behavioral attitude (ATT) (adapted from [10])

ATT1: Using LINE is a good idea;

ATT2: I like using LINE;

ATT3: Using LINE is a wise idea.

Subjective norms (SN) (adapted from [10])

SN1: People who are important to me think that I should use LINE;

SN2: People who influence me think that I should use LINE.

Perceived behavioral control (PBC) (adapted from [10])

PBC1: Using LINE is entirely within my control;

PBC2: I have the knowledge and ability to use LINE;

PBC3: I am able to skillfully use LINE.

Usage intention (UI) (adapted from [7])

UI1: I will frequently use LINE;

UI2: I will recommend LINE to others;

UI3: I will continue using LINE in the future. 